\title{
Pelatihan Pencegahan Penularan Penyakit Scabies dan Peningkatan Hidup Bersih dan Sehat Bagi Santriwan
}

\author{
Lensoni*1, Yulinar $^{2}$, Cut Rahmawati ${ }^{3}$, Meliyana $^{4}$, Erna Safitri ${ }^{5}$, Dini Rahmayani6 \\ 1,5,6Program Studi Kesehatan Masyarakat, Universitas Abulyatama \\ 2Program Studi Pendidikan Jasmani, Kesehatan dan Rekreasi, Universitas Abulyatama \\ 3,4Program Studi Teknik Sipil Universitas Abulyatama \\ *e-mail : soni@abulyatama.ac.id
}

\begin{abstract}
Scabies is a highly contagious skin disease in humans and other mammals caused by the parasitic mite sarcoptes scabiei. The main transmission of scabies is from direct physical contact, so scabies is susceptible to spread in a closed environment that is densely populated, such as houses, dormitories, and boarding schools. The location of the training is at Sulaimania Boarding School in Kuta Baro District, Aceh Besar Regency. The objective to be achieved from the training activities is to increase the knowledge of students at Sulaimania Islamic Boarding School, through the dissemination of knowledge about clean and healthy living behaviors to prevent scabies. The method used in the form of lectures, practice and frequently asked questions. Evaluation of training activities is carried out by distributing questionnaires before and after the activity. The evaluation showed that overall there was an increase approximately $60.34 \%$ in students' understanding of the prevention of scabies and healthy and clean living behaviors and the participants benefited from this training.
\end{abstract}

Keywords: scabies, disease, healthy and clean living behaviors

\begin{abstract}
Abstrak
Scabies adalah penyakit kulit yang sangat menular pada manusia dan mamalia lain yang disebabkan oleh tungau parasit sarcoptes scabiei. Penularan scabies yang utama adalah dari kontak fisik langsung sehingga scabies rentan menular di lingkungan tertutup yang padat penghuni, semisal rumah, asrama, dan pondok pesantren. Lokasi pengabdian berada di Pondok Pesantren Sulaimania di Kecamatan Kuta Baro, Kabupaten Aceh Besar. Tujuan yang ingin dicapai dari kegiatan pelatihan ini adalah meningkatkan pengetahuan kalangan santriwan pada Pondok Pesentren Sulaimania melalui sosialisasi tentang pengetahuan perilaku hidup bersih dan sehat untuk pencegahan penyakit scabies. Metode yang dilakukan berupa ceramah, praktek dan tanya jawab. Evaluasi kegiatan pelatihan dilakukan dengan menyebarkan kuesioner sebelum dan setelah kegiatan. Dari evaluasi yang dilakukan menunjukkan bahwa secara keseluruhan terjadi peningkatan pemahaman santriwan sebesar 60,34\% terhadap pecegahan penyakit scabies dan perilaku hidup sehat dan bersih dan peserta memperoleh manfaat dari pelatihan ini.
\end{abstract}

Kata kunci: scabies, penularan, perilaku hidup bersih dan sehat

\section{PENDAHULUAN}

Scabies adalah masalah global dan telah dilaporkan di Taiwan (Wang et al., 2012), Norwegia (Baccouche, Sellam, Guegan, Aractingi, \& Berenbaum, 2011), Jepang (Executive Committee of Guideline for the Diagnosis and Treatment of Scabies, 2017), dan banyak negara berkembang (Hay, Steer, Engelman, \& Walton, 2012). Diagnosis dini infeksi scabies penting karena sifatnya sangat menular. Namun scabies bukanlah penyakit menular yang diwajibkan untuk dilaporkan kepada organisasi kebersihan nasional di sebagian besar negara, mungkin karena tingkat kematian minimal dan sifat yang dapat diobati. Kondisi tempat tinggal, tempat tidur, tinggal di panti jompo, status klinis buruk, dan penggunaan jangka panjang kateter diidentifikasi sebagai faktor risiko yang signifikan untuk infeksi scabies. Keterlambatan diagnosis scabies dapat menyebabkan penyebaran langsung atau tidak langsung di rumah sakit, hanya saja harus waspada dengan pasien yang memiliki faktor risiko (Arifuddin, Kurniawan, \& Fitriani, 2016).

Scabies adalah penyakit kulit yang sangat menular pada manusia dan mamalia lain yang disebabkan oleh tungau parasit Sarcoptes scabiei (Griana, 2013). Wabah kudis scabietic secara 
berkala terjadi pada berbagai macam spesies hewan domestik dan liar dan dapat menyebabkan morbiditas dan mortalitas pada banyak spesies. Sarcoptes scabies terus menyebabkan masalah kesehatan pada sebagian besar hewan dan manusia (Chandler \& Fuller, 2019).

Penularan scabies biasanya karena kontak langsung atau tidak langsung. Keterlambatan dalam diagnosis dapat menyebabkan penyebaran kudis scabies (Aukerman, Curfman, Urias, \& Shayesteh, 2019) (Melo, Ribas, \& Encarnação, 2020). Pencegahan penyakit scabies, harus menggunakan manajemen yang tepat dari pengaturan panti jompo, pondok pesentren bahkan semua bentuk pendidikan boarding school termasuk pembersihan yang memadai dari pakaian, tempat tidur dan peralatan yang terkontaminas. Pada kombinasi dengan merawat semua pasien yang diduga scabies serta isolasi kontak adalah penting jika telah terjadi penularan penyakit tersebut (Marotta, Toni, Dallolio, Toni, \& Leoni, 2018). Penularan scabies yang utama adalah dari kontak fisik langsung. Hal ini yang menyebabkan mengapa scabies rentan menular di lingkungan tertutup yang padat penghuni, semisal rumah, asrama, dan pondok pesantren. Hal tersebut diatas melatar belakangi kegiatan pelatihan ini.

Secara umum kegiatan pelatihan ini bertujuan untuk meningkatkan pengetahuan kalangan siswa pada Pondok Pesentren Sulaimania yang terletak di Kecamatan Kuta Baru Kabupaten Aceh Besar, melalui sosialisasi tentang pengetahuan perilaku hidup bersih dan sehat untuk pencegahan penyakit scabies. Diharapkan dari kegiatan pelatihan melalui sosialisasi pencegahan penyakit scabies dikalangan santriwan pada Pondok Pesantren Sulaimaniya ini dapat memberikan kontribusi positif untuk pencegahan penularan dan terjadinya penyakit scabies.

\section{METODE}

Dalam melaksankan kegiatan pelatihan ini, kerangka berpikir untuk memecahkan masalah digambarkan seperti pada Gambar 1. Dari permasalahan yang muncul disusun berbagai alternatif untuk memecahkan masalah. Selanjutnya dari berbagai alternatif, dipilih alternatif yang paling mungkin dilaksanakan.

\section{Permasalahan}

- Para santriwan kurang memahami tentang prilaku hidup bersih dan sehat.

- Para santriwan kurang memahami bagaimana cara berprilaku hidup bersih dan sehat.

- Para santriwan tidak mengetahui bagaimana cara pencegahan penyakit scabies

\section{Metode Kegiatan}

- Penyampaian materi dan diskusi tentang pencegahan penularan scabies dan perilaku hidup bersih dan sehat.

- Tanya jawab tentang pencegahan penularan scabies dan perilaku hidup bersih dan sehat
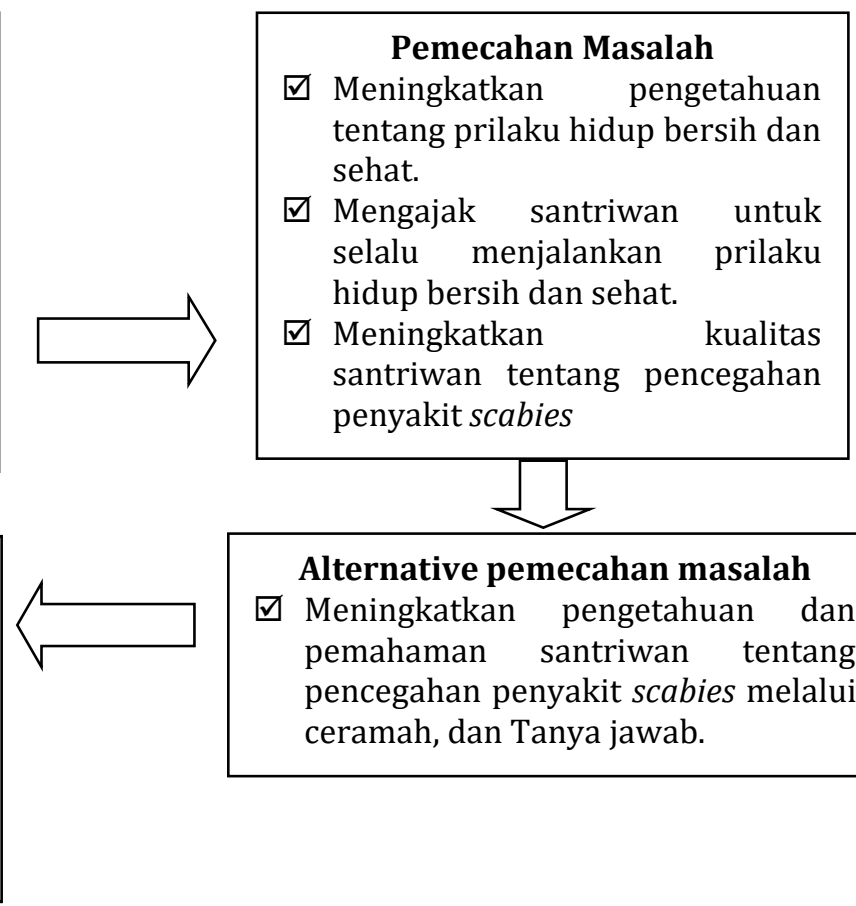

Alternative pemecahan masalah

ఐ Meningkatkan pengetahuan dan pemahaman santriwan tentang pencegahan penyakit scabies melalui ceramah, dan Tanya jawab.

Gambar 1. Bagan skematis pemecahan masalah. 
Berdasarkan kerangka berpikir tersebut, maka metode yang digunakan dalam kegiatan ini adalah sebagai berikut :

1. Ceramah dan Diskusi.

Kegiatan ceramah dan diskusi dilakukan untuk memberikan pemahaman peserta tentang perilaku hidup bersih dan sehat (PHBS). Materi ini akan diberikan oleh mahasiswa yang menguasai materi perilaku hidup bersih dan sehat dan di bantu oleh dosen yang ikut dalam kegiatan ini. Materi yang disampaikan meliputi materi pengenalan penyakit scabies, pencegahan penularannya, perilaku hidup bersih dan sehat dan bagaimana cara untuk melakukan praktek perilaku hidup bersih dan sehat tersebut.

2. Praktek.

Kegiatan ini merupakan lanjutan dari kegiatan diatas yang secara khusus bertujuan untuk meningkatkan kemampuan santriwan pada Pondok Pesantren Sulaimaniya dalam memahami pencegahan penyakit scabies serta tentang perilaku hidup bersih dan sehat. Kegiatan ini diisi dengan praktek cara melakukan perilaku hidup bersih dan sehat untuk pencegahan penularan penyakit scabies.

3. Evaluasi

Pada akhir kegiatan pelatihan dilakukan evaluasi terhadap hasil pelatihan bagi peserta. Evaluasi ini bertujuan untuk mengevaluasi pemahaman dan pengetahuan peserta terhadap materi yang telah diberikan serta sejauh mana manfaat yang dirasakan peserta dari pelatihan ini.

\section{HASIL DAN PEMBAHASAN}

Scabies adalah penyakit kulit yang sangat menular pada manusia dan mamalia lain yang disebabkan oleh tungau parasit sarcoptes scabies. Penularan scabies yang utama adalah kontak fisik langsung. Pencegahan kontak fisik menjadi langkah yang paling tepat untuk menekan peluang penyebaran scabies di suatu area. Berikut adalah beberapa pedoman pencegahan scabies :

1. Mengenali gejala scabies

Langkah awal pencegahan scabies dapat dilakukan dengan mengenali gejala scabies pada orang yang terinfeksi. Untuk mengetahui jika seseorang terkena scabies dapat dilihat melalui tanda-tanda berikut ini:

- Terdapat bintik merah atau lesi yang menonjol pada kulit (bintil).

- Sering menggaruk bagian kulit yang terdapat bintil merah.

- Kesulitan tidur di malam hari karena rasa gatal di bagian bintil merah.

- Bintil merah muncul pada bagian tangan, siku, ketiak, sela-sela jari, pinggang

2. Mewaspadai faktor risiko scabies

Dalam upaya pencegahan kudis, orang dengan faktor risiko scabies sebaiknya lebih mewaspadai penularan penyakit kulit ini. Tungau bisa berpindah lebih cepat dari satu orang ke orang lainnya dalam tempat tertutup dimana banyak orang yang melakukan kontak fisik yang dekat antara satu sama lain.

3. Segera memeriksakan diri ke dokter

Jika seseorang melakukan kontak fisik terus-menerus dengan orang yang mengalami gejala scabies sekaligus termasuk ke dalam kondisi faktor risiko scabies, sebaiknya segera memeriksakan diri ke dokter.

4. Menghindari kontak fisik

Scabies menular lewat kontak fisik antar kulit yang sangat dekat dan berkepanjangan, seperti tidur bersama setiap malam. Oleh karena itu sebagai bentuk pencegahan, sebisa mungkin sebaiknya menghindari kontak fisik dengan anggota keluarga atau orang lain yang mengidap scabies.

5. Membasmi tungau yang menempel

Prinsip utama dalam pencegahan scabies adalah membunuh tungau yang masih hidup. Cuci semua pakaian, sprei, dan selimut yang digunakan oleh penderita menggunakan air panas 
guna membasmi tungau yang tertinggal. Setelah dicuci, keringkan barang-barang tersebut dalam suhu yang panas dalam waktu lama.

6. Menjaga kebersihan rumah

Sementara itu, perabot rumah dan barang-barang yang berpotensi menjadi tempat tungau berkembang biak, seperti sofa, karpet, atau Kasur juga perlu dibersihkan. Selain itu pencegahan tungau penyebab scabies di rumah juga perlu didukung dengan kelembapan ruangan yang optimal.

7. Tidak menggunakan barang secara bersamaan

Tungau penyebab scabies juga dapat ditularkan lewat barang-barang pribadi yang dipakai secara bergantian seperti pakaian, handuk, atau sprei tempat tidur. Pencegahan bisa dilakukan dengan memisahkan penggunaan barang dengan anggota keluarga yang mengidap scabies.

Perilaku hidup bersih dan sehat dalah semua perilaku kesehatan yang dilakukan atas kesadaran sehingga anggota keluarga atau keluarga dapat menolong dirinya sendiri di bidang kesehatan dan berperan aktif dalam kegiatan-kegiatan kesehatan di masyarakat. Perilaku hidup bersih dan sehat pada dasarnya merupakan upaya untuk menularkan pengalaman mengenai perilaku hidup dan sehat melalui individu, kelompok ataupun masyarakat luas dengan jalu-jalur komunikasi sebagai media berbagi komunikasi.

Manfaat perilaku hidup bersih dan sehat secara umum adalah meningkatkan kesadaran masyarakat untuk mau menjalankan hidup bersih dan sehat. Hal tersebut dilakukan agar masyarakat dapat mencegah dan menanggulangi masalah kesehatan. Perilaku hidup bersih dan sehat di pesantren merupakan langkah untuk memberdayakan santriwan, guru dan masyarakat lingkungan sekolah agar mau dan dapat melakukan perilaku hidup bersih dan sehat dalam menciptakan sekolah yang sehat. Beberapa perilaku hidup sehat dan bersih yang dapat diterapkan di sekolah antara lain :

- Mencuci tangan dengan sabun sebelum dan sesudah makan

- Mengonsumsi jajanan sehat

- Olahraga yang teratur

- Memberantas jentik nyamuk

- Tidak merokok

- Membuang sampah pada tempatnya

Evaluasi terhadap kegiatan pelatihan ini dilaksanakan dengan menyebarkan kuesioner kepada para peserta sebelum pelatihan (pretest) dan setelah pelatihan (post-test). Pretest dan post-test bertujuan untuk mengetahui kemampuan (work volition) dari peserta terhadap manfaat kegiatan (Mulyawan, Hidayat, \& Badrujaman, 2020). Indikator yang digunakan sebagai tolok ukur meningkatnya pengetahuan dan pemahaman santriwan adalah telah mampu dalam mendeskripsikan apa itu scabies dan penyebabnya, bagaimana cara pencegahan penularan scabies, bagaimana cara perilaku hidup bersih dan sehat, serta masalah-masalah kesehatan yang sering terjadi pada masyarakat. Selain itu santriwan juga dapat mempraktekkan bagaimana perilaku hidup bersih dan sehat yang dapat dijadikan acuan dalam melakukan perilaku hidup bersih dan sehat sehari-hari. Pelaksanaan kegiatan seperti terlihat pada Gambar 2. Dari hasil evaluasi diperoleh bahwa secara keseluruhan terjadi peningkatan pemahaman terhadap materi pelatihan dan peserta memperoleh manfaat dari pelatihan ini. 

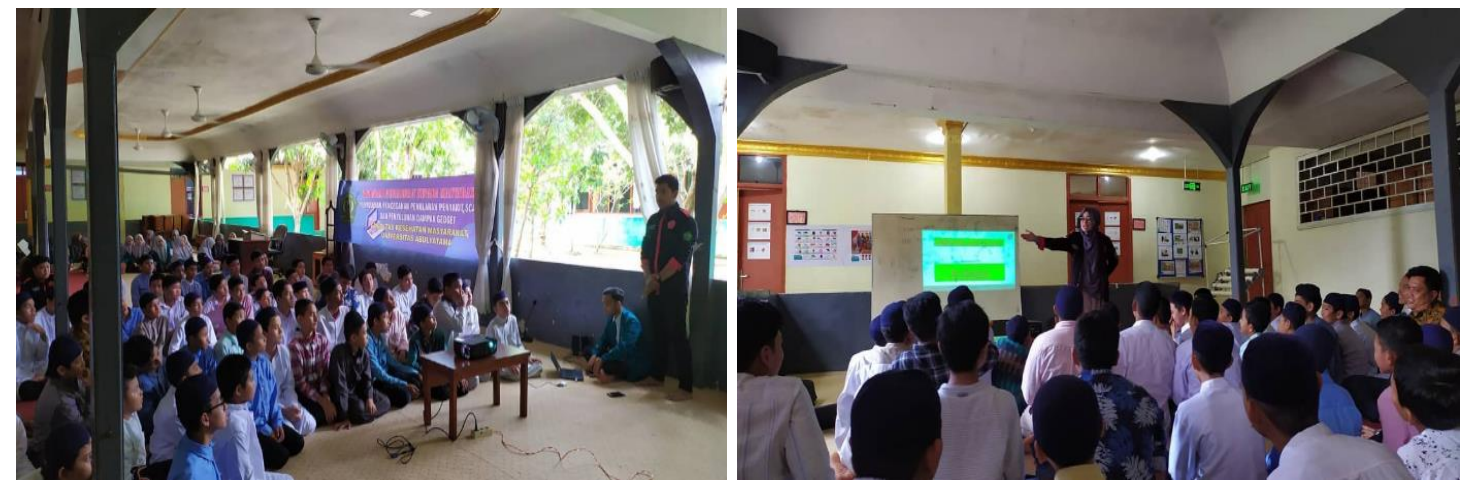

Gambar.2 Pelaksanaan kegiatan pelatihan

Berdasarkan hasil pretest dan post-test yang diberikan terlihat ada peningkatan pemahaman santriwan terhadap materi yang diberikan. Nilai rata-rata sebelum kegiatan sebesar 58 dan setelah kegiatan sebesar 95, dengan demikian terjadi peningkatan pemahaman santiwan sebesar 60,34\%. Selengkapnya hasil pretest dan post-test dapat dilihat pada Gambar 3.

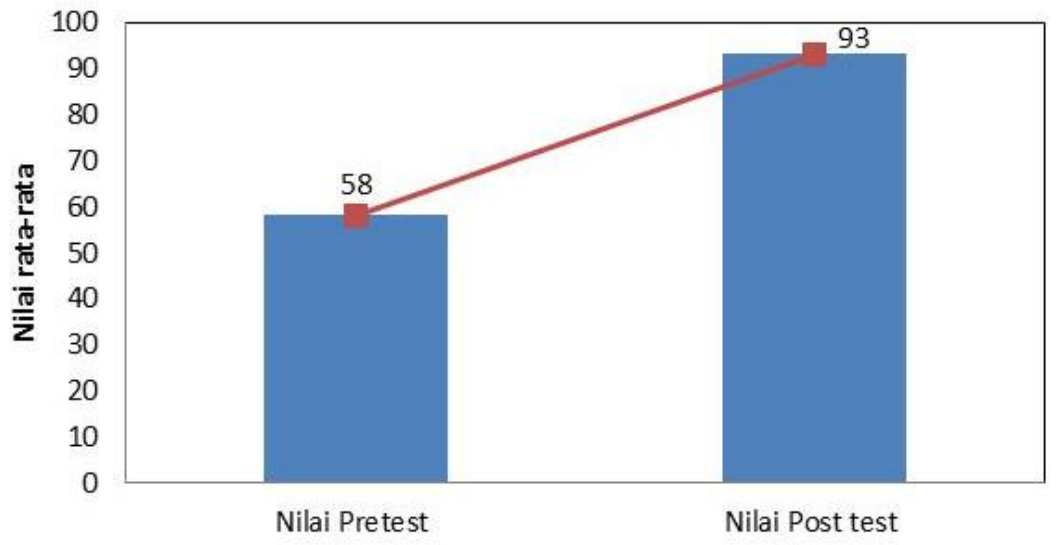

Gambar 3. Hasil pretest dan post-test kegiatan

\section{KESIMPULAN}

Pelakasanaan kegiatan pelatihan pencegahan penularan penyakit scabies dan peningkatan hidup bersih dan sehat bagi santriwan berjalan dengan lancer sampai dengan tahap akhir. Kegiatan ini berdamapak positif bagi peningkatan pemahaman dan kemampuan mempraktekkan hidup bersih dan sehat. Berdasarkan evaluasi terjadi peningkatan nilai ratarata pada sebelum dan sesudah dilaksanakannya pelatihan. Terjadi peningkatan pemahaman santriwan sebesar $60,34 \%$ dari hasil pretest dan post-test.

Pemahaman santriwan terbentuk dengan dialog dan pemberian contoh praktek hidup sehat sehari-hari.

\section{DAFTAR PUSTAKA}

Arifuddin, A., Kurniawan, H., \& Fitriani, F. (2016). Faktor Risiko Kejadian Scabies di Rumah Sakit Umum Anutapura Palu. Medika Tadulako, 3(3), 40-59.

Aukerman, W., Curfman, K., Urias, D., \& Shayesteh, K. (2019). Norwegian Scabies management after prolonged disease course: A case report. International Journal of Surgery Case Reports, 61, 180-183. https://doi.org/10.1016/j.ijscr.2019.07.025 
Baccouche, K., Sellam, J., Guegan, S., Aractingi, S., \& Berenbaum, F. (2011). Crusted Norwegian scabies, an opportunistic infection, with tocilizumab in rheumatoid arthritis. Joint Bone Spine, 78(4), 402-404. https://doi.org/10.1016/j.jbspin.2011.02.008

Chandler, D. J., \& Fuller, L. C. (2019). A Review of Scabies: An Infestation More than Skin Deep. Dermatology, 235(2), 79-80. https://doi.org/10.1159/000495290

Executive Committee of Guideline for the Diagnosis and Treatment of Scabies. (2017). Executive Committee of Guideline for the Diagnosis and Treatment of Scabies. Guideline for the diagnosis and treatment of scabies in Japan (third edition): Executive Committee of Guideline for the Diagnosis and Treatment of Scabies. J Dermatol, 44(9), 991-1014.

Griana, T. P. (2013). Scabies: Penyebab, Penanganan dan Pencegahannya. El-Hayah, 4(1), 3746.

Hay, R. J., Steer, A. C., Engelman, D., \& Walton, S. (2012). Scabies in the developing world-its prevalence, complications, and management. Clinical Microbiology and Infection, 18(4), 313-323. https://doi.org/10.1111/j.1469-0691.2012.03798.x

Marotta, M., Toni, F., Dallolio, L., Toni, G., \& Leoni, E. (2018). Management of a family outbreak of scabies with high risk of spread to other community and hospital facilities. American Journal of Infection Control, 46(7), 808-813.

Melo, E. D., Ribas, C. B. da R., \& Encarnação, I. C. L. (2020). Digital dermoscopy: a complementary method in the diagnosis of scabies. Anais Brasileiros de Dermatologia, (xx). https://doi.org/10.1016/j.abd.2019.11.014

Mulyawan, G., Hidayat, D. R., \& Badrujaman, A. (2020). Program Bimbingan Karir Untuk Meningkatkan Kemauan Kerja Siswa Kesetaraan Paket C di Kota Serang. Dinamisia, 4(2), 250-254.

Wang, C. H., Lee, S. C., Huang, S. S., Kao, Y. C., See, L. C., \& Yang, S. H. (2012). Risk factors for scabies in Taiwan. Journal of Microbiology, Immunology and Infection, 45(4), 276-280. https://doi.org/10.1016/j.jmii.2011.12.003 